Published in final edited form as:

Fertil Steril. 2017 August ; 108(2): 312-319. doi:10.1016/j.fertnstert.2017.05.020.

\title{
Urinary triclosan concentrations and diminished ovarian reserve among women from a fertility clinic
}

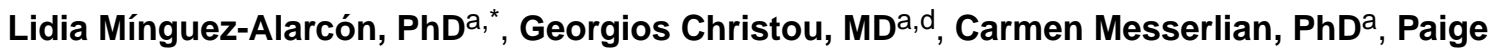 \\ L. Williams, $\mathbf{P h D}{ }^{b, c}$, Courtney C. Carignan, $\mathbf{P h D}^{\mathrm{a}}$, Irene Souter, $\mathbf{M D}^{\mathrm{d}}$, Jennifer B. Ford, $\mathbf{R N}^{\mathrm{a}}$, \\ Antonia M. Calafat, $\mathrm{PhD}^{\mathrm{e}}$, and Russ Hauser, $\mathrm{MD}^{\mathrm{a}, \mathrm{b}, \mathrm{d}}$ for the EARTH Study Team \\ aDepartment of Environmental Health, Harvard T.H. Chan School of Public Health, Boston

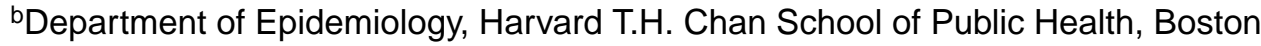 \\ 'Department of Biostatistics, Harvard T.H. Chan School of Public Health, Boston \\ dVincent Obstetrics and Gynecology, Massachusetts General Hospital, Boston \\ eNational Center for Environmental Health, Centers for Disease Control and Prevention, Atlanta
}

\section{Abstract}

Objective-To investigate the association between urinary triclosan concentrations and antral follicle count (AFC), a well-accepted marker of ovarian reserve, among women from a fertility center.

Design-Prospective cohort study.

Setting-Women attending the Massachusetts General Hospital Fertility Center.

Patient(s)—A total of 109 women.

Intervention(s) -None. Urinary triclosan concentrations were quantified by online solid phase extraction-high performance liquid chromatography-isotope dilution tandem mass spectrometry.

Main outcomes measure(s)-AFC through transvaginal ultrasonography on the 3rd day of an unstimulated menstrual cycle or on the 3rd day of a progesterone withdrawal bleed.

\footnotetext{
*Correspondence: Lidia Mínguez-Alarcón, PhD, MPH. Department of Environmental Health, Harvard T. H. Chan School of Public Health, 665 Huntington Ave., Boston, MA 02115 (lminguez@ hsph.harvard.edu).

Conflict of Interest: None of the authors has any conflicts of interest to declare. The findings and conclusions in this report are those of the authors and do not necessarily represent the official position of the Centers for Disease Control and Prevention (CDC). Use of trade names is for identification only and does not imply endorsement by the CDC, the Public Health Service, or the US Department of Health and Human Services.

Author's Contribution to Manuscript: R.H. and P.L.W were involved in study concept and design, and critical revision for important intellectual content of the manuscript; P.L.W contributed to method modification and provided statistical expertise; L.M.A and G.C. analyzed data, drafted the manuscript and had a primary responsibility for final content; L.M.A, G.C., C.M., C.C.C., P.L.W. and R.H. interpreted the data; C.M. and C.C.C. reviewed the statistical analysis; I.S, A.M.C and J.B.F were involved in acquisition of the data. All authors were involved in the critical revision of the manuscript and approved the final manuscript.

Publisher's Disclaimer: This is a PDF file of an unedited manuscript that has been accepted for publication. As a service to our customers we are providing this early version of the manuscript. The manuscript will undergo copyediting, typesetting, and review of the resulting proof before it is published in its final citable form. Please note that during the production process errors may be discovered which could affect the content, and all legal disclaimers that apply to the journal pertain.
} 
Results-The geometric mean (GM) (95\% CI) of the specific gravity (SG)-adjusted urinary triclosan concentrations for the 225 samples provided by the 109 women was $13.0(8.9,19.1)$ $\mu \mathrm{g} / \mathrm{L}$. Women had median (interquartile range, IQR) AFC of $13(8,18)$. SG-adjusted urinary triclosan concentrations were inversely associated with $\mathrm{AFC}(-4 \%, 95 \% \mathrm{CI}=-7 \%,-1 \%$, pvalue $=0.009$ ). Women with triclosan concentrations above the median had lower AFC compared to those with triclosan concentrations equal to or below the median, with an adjusted difference of -3.2 (95\% CI -3.9, -1.6) among those with body mass index (BMI) $<25 \mathrm{~kg} / \mathrm{m}^{2}$ and $-1.8(95 \%$ CI $-3.2,-0.3)$ among those who were $<35$ years old.

Conclusion(s)-SG-adjusted urinary triclosan concentrations were inversely associated with AFC in women seeking care at a fertility center. This association was modified by age and BMI, with younger and leaner women showing larger decreases in AFC.

\section{Keywords}

triclosan; ovarian reserve; antral follicle count; infertility

\section{Introduction}

Triclosan (2,4,4' -trichloro-2' -hydroxydiphenyl ether) is a lipid-soluble, chlorinated aromatic compound with broad-spectrum antibacterial properties used for over forty years as an ingredient in personal care products such as detergents, soaps, lotions, toothpaste and shampoos $(1,2)$. Triclosan can be used as a plastic additive impregnated into toys, medical devices, household, veterinary, and industrial products $(1,2)$. Due to its widespread use, there is the potential for the general population to be exposed to triclosan through dermal and mucosal contact with consumer products, and through ingestion of contaminated food or water (3-5). Triclosan has a half-life in plasma of 19 hours with the major fraction of it being eliminated primarily in urine within the first 24 hours (3-5). The detection of triclosan in urine in nearly 75\% of the 2003-2004 National Health and Nutrition Examination Survey (NHANES) participants confirms the ubiquity of the exposure (4). Although triclosan has also been detected in breast milk $(6,7)$, urine is the optimal matrix for measuring nonpersistent, semivolatile environmental chemicals that are biotransformed to hydrophilic, polar metabolites such as triclosan (8).

The use of triclosan was not highly regulated in the US until very recently due to its FDA classification of generally recognized as safe and effective (GRAS/GRAE). Concerns related to health effects of other organochlorines that were previously banned, partially led the FDA in September 2016 to issue a final rule: triclosan and another 18 ingredients used in overthe-counter consumer antiseptic soaps are misbranded and are new drugs for which approved new drug applications are required for marketing (9). Similar policies have been implemented in Canada and in the European Union (10-12).

In several experimental studies using various animal models, triclosan has been implicated as an endocrine disruptor. Perinatal and pubertal exposed rats showed decreased levels of thyroxine, with the effect to be more prominent amongst those animals treated with the highest doses of triclosan $(13,14)$. In in vitro studies, triclosan enhanced ovarian and breast cancer cell growth and also impaired human endometrial stromal cell proliferation, 
migration and decidualization (15-17). Female reproductive system development and endocrine function are adversely affected by triclosan in both mice and rats. Triclosan increases estrogen hormonal levels and modulates its actions on target organs, such as the uterus (18). Additionally, triclosan causes disruption of blastocyst implantation in mice and alters ovine placental estrogen synthesis leading to adverse pregnancy outcomes (19).

Human studies exploring the effect of triclosan exposure on reproductive health are limited. In a case-control study among sub-fertile men, triclosan affected the negative feedback loop of luteinizing hormone secretion due to its presumptive adverse impact on Leydig cells (20). Among participants in the Maternal-Infant Research on Environmental Chemicals (MIREC) Study, women with higher urinary triclosan concentrations had increased time to pregnancy, an indicator of fecundability, when compared to women with lower urinary triclosan concentrations (21). However, this negative association was not confirmed among women in The Longitudinal Investigation of Fertility and the Environment (LIFE) Study (22). To date, the potential effect of triclosan on ovarian reserve has not been examined. Antral follicle count (AFC) is a well-accepted marker of ovarian reserve used primarily in clinical settings to assess fecundability in women with suspected infertility and make decisions regarding their treatment options (23). This study aimed to prospectively explore whether urinary triclosan concentrations were associated with AFC among women seeking care at a fertility center.

\section{Methods}

\section{Study population}

Study participants were women enrolled in the Environment and Reproductive Health (EARTH) Study, an ongoing prospective cohort established in 2004 to evaluate environmental and dietary determinants of fertility (24). Women between 18 and 45 years at enrollment who planned to use their own gametes were eligible to participate in the study. Approximately $60 \%$ of women contacted by the research nurses were enrolled. This prospective analysis included women who provided at least one spot urine sample for the measurement of triclosan concentrations prior to the measurement of their AFC at the Massachusetts General Hospital (MGH). Fertility Center between the years of 2007 and 2016 ( $\mathrm{n}=118)$. Due to insurance coverage limitations, women undergoing infertility evaluation and treatment have their AFC measurement only once a year. Therefore, the urine sample collections preceded the AFC measurement up to a year for each woman. Of these, 8 women (7\%) with a diagnosis of polycystic ovarian syndrome (PCOS) as noted in their medical records were not included in this analysis because these observations were given a code, not a count. We also excluded one woman who was missing a baseline infertility diagnosis, resulting in a final study sample of 109 women for this analysis. The study was approved by the Human Studies Institutional Review Boards of the MGH, the Harvard T.H. Chan School of Public Health, and the Centers for Disease Control and Prevention (CDC). Participants signed an informed consent after the study procedures were explained by trained research study staff and all questions were answered. 


\section{Assessment of the exposure}

Each woman provided a spot urine sample at study entry, and twice during each subsequent treatment cycle, corresponding to days 3-9 of the early/mid follicular phase of the cycle and in the preovulatory phase, and again at the time of oocyte retrieval or intrauterine insemination. All urine samples collected prior to the AFC scan date (ranging from 1 to 10 urine samples per woman) were included in the analysis. Urine was collected in a sterile, clean polypropylene specimen cup at the MGH Fertility Center. Specific gravity (SG) was used to adjust triclosan concentrations for urinary dilution. SG was measured at room temperature and within several hours (typically within one hour) of the urine collection using a handheld refractometer (National Instrument Company, Inc., Baltimore, MD, USA) that was calibrated with deionized water before each measurement. The urine was then divided into aliquots, frozen, and stored at $-80{ }^{\circ} \mathrm{C}$. Samples were shipped on dry ice overnight to the $\mathrm{CDC}$ where they were stored at or below $-40{ }^{\circ} \mathrm{C}$ until analysis.

The concentration of total (free plus conjugated) triclosan in $100 \mu \mathrm{L}$ of urine was determined using an online solid-phase extraction coupled to high-performance liquid chromatographyisotope dilution-tandem mass spectrometry approached described before (25). The limit of detection (LOD) was $2.3 \mu \mathrm{g} / \mathrm{L}$. In addition to study samples, each analytical run included low-concentration and high-concentration quality control urine pools and reagent blanks to assure the accuracy and reliability of the data (25). Triclosan concentrations were adjusted for dilution using the following formula: $\mathrm{Pc}=\mathrm{P}[(1.015-1) / \mathrm{SG}-1]$, where $\mathrm{Pc}$ is the SGcorrected triclosan concentration $(\mu \mathrm{g} / \mathrm{L}), \mathrm{P}$ is the measured triclosan metabolite concentration $(\mu \mathrm{g} / \mathrm{L})$ of the urine sample, and 1.015 is the mean SG concentration in the study population $(26,27)$. For women with only one urine sample $(64 \%)$, the triclosan concentration for that single sample was used as the woman-specific urinary concentration. Due to the high within-woman variability of urinary triclosan concentrations [intraclass correlation coefficient $(\mathrm{ICC})(95 \% \mathrm{CI})=0.06(0.03,0.11)$, we calculated the geometric mean for women with more than one sample (36\%) by averaging all urine samples collected up to one year before the AFC measurement. Triclosan concentrations below the LOD were assigned a value equal to the LOD divided by the square root of 2 prior to SG adjustment.

\section{Assessment of the outcome}

All women participating in the study underwent an evaluation of ovarian AFC through transvaginal ultrasonography by one of the MGH reproductive endocrinology and infertility physicians on the 3rd day of an unstimulated menstrual cycle or on the 3rd day of a progesterone withdrawal bleed. No fertility medications were used in the cycle preceding the ultrasonographic determination of the AFC. This analysis included one AFC per woman. Of the 109 women, $2(2 \%)$ women had $\mathrm{AFC}>30$. Because women in the current study had a median (interquartile range, IQR) AFC of $13(8,18)$, in order to reduce the influence of these high values, we truncated AFC at 30.

\section{Assessment of covariates}

The participant's date of birth was collected at entry, and weight and height were measured by trained study staff. Body mass index (BMI) was calculated as weight (in kilograms) per height (in meters) squared. The detailed take-home questionnaire contained questions on 
lifestyle factors, reproductive health, and medical history. Time spent in leisure time physical and sedentary activities was assessed using a validated questionnaire (28). Infertility diagnosis was abstracted from electronic medical records. Follicle-stimulating hormone was measured in serum, collected on the third day of the menstrual cycle, using an automated electrochemiluminescence immunoassay at the MGH Core Laboratory as previously described (29).

\section{Statistical analysis}

Demographic and baseline reproductive characteristics of the women were presented using median \pm interquartile ranges (IQRs) or percentages. Associations between SG-adjusted urinary triclosan concentrations and demographic and baseline reproductive characteristics were evaluated using Kruskal-Wallis tests for continuous variables and chi-squared tests for categorical variables (or Fisher's exact test where appropriate). Poisson regression models were used to estimate the association of SG-adjusted urinary triclosan concentrations with AFC. Women's exposure to triclosan, estimated from the triclosan SG-adjusted urinary concentration, was treated as a continuous variable. Because $25 \%$ of the triclosan concentrations were below the LOD and the substitution of these concentrations for a value equal to the LOD divided by the square root of 2 could cause some misclassification of the exposure, triclosan concentrations were also divided in two groups (at above and below the median of SG-adjusted urinary triclosan concentrations for this study population). To allow for better interpretation of the results, population marginal means (30) were presented adjusted for all the covariates in the model (with covariates at their average values).

Confounding was assessed using prior knowledge on biological relevance and descriptive statistics from our study population through the use of directed acyclic graphs (31). The variables considered as potential confounders included factors previously related to reproductive outcomes in this and other studies, and factors associated with triclosan exposure and reproductive outcomes in this study. Final models were adjusted for age (years), BMI $\left(\mathrm{kg} / \mathrm{m}^{2}\right.$ ), year of sample collection ( $\_2012$ and $>2012$ ), physical activity (hr/ week), and baseline infertility diagnosis (male, female and unexplained). A sensitivity analysis was conducted to test for effect modification by age ( $<35$ years vs. $\geq 35$ years) and BMI ( $<25 \mathrm{~kg} / \mathrm{m}^{2}$ vs. $\geq 25 \mathrm{~kg} / \mathrm{m}^{2}$ ), well-known predictors of women's fertility (32-35), on the relationship between SG-adjusted urinary triclosan concentrations (above and below the median) and AFC by adding a cross product term to the final multivariate model. Statistical analyses were performed with SAS (version 9.4; SAS Institute Inc., Cary, NC, USA).

\section{Results}

This analysis included 109 women with median (IQR) age of $36(32,38)$ years and BMI of $23.0(20.9,26.5) \mathrm{kg} / \mathrm{m}^{2}$ (Table 1). The majority of the participants were Caucasian (78\%), with a college degree or higher (80\%), and most had never smoked (73\%). Most of the women $(78 \%)$ had undergone infertility evaluation and $37 \%$ had been treated for infertility before their enrollment in the study. Unexplained infertility was the primary infertility diagnosis at enrollment (50\%). Women with SG-adjusted urinary triclosan concentrations above the median were less likely to have unexplained infertility diagnosis at enrollment, 
had more leisure-time physical activity and higher levels of FSH in day 3, compared with other women study participants who had SG-adjusted urinary triclosan concentrations below the median ( $38 \%$ vs. $61 \%, 6.5$ vs. $4.0 \mathrm{hr} /$ week, and 6.4 vs. $6.9 \mathrm{IU} / \mathrm{L}$, respectively). No other baseline characteristics differed substantially across these two groups (Table 1). The GM (95\% CI) and median (IQR) of the SG-adjusted urinary triclosan concentrations for the 225 samples provided by the 109 women were $13.0(8.9,19.1)$ and $7.9(<\mathrm{LOD}, 33.6) \mu \mathrm{g} / \mathrm{L}$, respectively (Table 2). Of the total of 225 urine samples, 55 (25\%) had triclosan concentrations below the LOD. Seventy (64\%) women provided one urine sample and 39 (36\%) women provided more than one sample. The median (IQR) AFC among the 109 women was $13(8,18)$ with a minimum and maximum of 2 and 30 follicles, respectively (data not shown).

SG-adjusted urinary triclosan concentrations were inversely associated with AFC in unadjusted models as well as models adjusted for age (years), BMI $\left(\mathrm{kg} / \mathrm{m}^{2}\right)$, year of sample collection ( 2012 and >2012), total leisure-time physical activity (hr/week) and infertility diagnosis (male, female and unexplained) (Table 3). In unadjusted models, one $\log _{\mathrm{e}}$ unit increase in SG-adjusted urinary triclosan concentrations was associated with a 3\% decrease $(95 \% \mathrm{CI}=-5 \%,-2 \%)$ in AFC (p-value $=0.04)$. This association was strengthened after adjustment for covariates $(-4 \%, 95 \% \mathrm{CI}=-7 \%,-1 \%$, p-value $=0.009)$. The negative association between SG-adjusted urinary triclosan concentrations and AFC remained, although was no longer statistically significant, when triclosan concentrations were divided by the median. Specifically, women who had SG-adjusted urinary triclosan concentrations above the median had a decrease in AFC of $1.0(95 \% \mathrm{CI}=-2.0,0.3)$ as compared to women who had concentrations equal to or below the median in the adjusted model ( $\mathrm{p}$-value $=0.18$ ) (Table 3). Since the cutoff for the year of sample collection covariate ( $ک 2012$ and >2012) was selected arbitrary, we also performed models included this covariate as continuous and results did not change (data not shown). In addition, we corroborated the negative relationships when we excluded from the models a total of 14 women who were diagnosed at enrollment with ovulatory infertility since women with this diagnosis may have altered AFC (data not shown).

In sensitivity analysis where we investigated whether age or BMI or age modified the associations between SG-adjusted urinary triclosan concentrations (above vs. below the median) and AFC, we observed some evidence of effect modification (Figure 1). The negative association between SG-adjusted urinary triclosan concentrations and AFC was stronger among lean women $\left(<25 \mathrm{~kg} / \mathrm{m}^{2}\right.$ ) compared to overweight/obese women ( $\geq 25$ $\left.\mathrm{kg} / \mathrm{m}^{2}\right)(\mathrm{p}$-interaction $=0.004)$ and also stronger among younger women $(<35$ years $)$ compared to older women ( 235 years) ( -interaction $=0.65$ ), although the effect of modification by age was not as robust compared to BMI. Specifically, among lean women, on average, those with triclosan concentrations above the median had lower AFC compared to women whose triclosan concentrations were equal to or below the median (adjusted difference, $95 \% \mathrm{CI}=-3.2,-3.9$ to -1.6$)(\mathrm{p}$-value $=0.003)$. In addition, women who were $<35$ years and had triclosan concentrations above the median, had, on average, a lower AFC compared to women with triclosan concentrations equal to or below the median (adjusted difference, $95 \% \mathrm{CI}=-1.8,-3.2$ to -0.3$)(\mathrm{p}$-value $=0.12)($ Figure 1$)$. 


\section{Discussion}

To our knowledge, this is the first study to investigate the association of urinary triclosan concentrations with a biomarker of ovarian aging among women from a fertility center. We found that SG-adjusted urinary triclosan concentrations were inversely associated with AFC, which is considered a well-accepted marker of ovarian reserve among women seeking infertility treatments (23). Moreover, the negative association of urinary triclosan concentrations with AFC was stronger among lean women $\left(<25 \mathrm{~kg} / \mathrm{m}^{2}\right)$ and younger women $(<35$ years $)$.

Two published studies examined the relationship between urinary triclosan concentrations and fecundity, measured as time to pregnancy $(21,22)$. Consistent with our results, Velez and coworkers concluded that urinary triclosan concentrations were inversely associated with fecundity among 2,001 Canadian women in the MIREC Study who had comparable urinary triclosan concentrations to women in our study (medians $=8.3$ and $7.9 \mu \mathrm{g} / \mathrm{L}$, respectively) (21). This negative association was observed when they compared women in the highest quartile of urinary triclosan concentrations $(>72 \mu \mathrm{g} / \mathrm{L}$ ) with the three lower quartiles as the reference group [fecundability odds ratio (FOR) (95\% CI): 0.84 (0.720.97)]. Smarr and colleagues did not find any association between urinary triclosan concentrations and fecundity among US women in the LIFE Study [FOR (95\% CI): 1.01 (0.95-1.06)] (22), who had considerable higher urinary triclosan concentrations compared with women in the MIREC Study and in our study (medians=16.8 $\mu \mathrm{g} / \mathrm{g}$ creatinine, 8.3 and $7.9 \mu \mathrm{g} / \mathrm{L}$, respectively). Given the few studies and inconsistent findings, the potential role of triclosan on adverse female reproductive outcomes remains undefined.

The exact mechanism by which triclosan affects ovarian reserve has not been thoroughly examined yet. Several experimental studies have demonstrated that triclosan may modify estrogen-dependent responses. In vivo studies showed that orally administered triclosan may potentiate the effect of estrogen on the uterus causing hypertrophy of the tissue in developing female Wistar rats. However, no change on ovary histopathology or follicular development was observed (18). Additionally, elevated urinary concentrations of endogenous estradiol have been detected following subcutaneous injection of triclosan in cycling and inseminated female CF1 mice (36). Similarly, higher doses of triclosan may cause disruption of intrauterine blastocyst implantation in these mice (19). Triclosan was also found to be an inhibitor of estradiol and estrone sulfation in ovine placenta (37). In vitro studies also support the fact that triclosan has estrogenic and androgenic properties by impairing the interaction between estradiol and testosterone with their respective receptors acting as both an agonist and antagonist of estrogens and androgens (38-40). Therefore, it can be hypothesized that triclosan exhibits its potential deleterious effects on the human ovary by either affecting endogenous ovarian steroidogenic pathways and estrogen production or sex steroid hormones hepatic clearance. Moreover, triclosan may impair the interaction between estrogens with their respective receptors and therefore disrupting follicular formation and development. However, further research is required to elucidate the underlying mechanisms. 
Urinary triclosan concentrations in our study population were similar to or lower than have been observed in other populations. Pregnant women in Puerto Rico (41) and France (42) also had considerably higher urinary triclosan concentrations compared to women included in our study (medians=26.2 and $24.1 \mu \mathrm{g} / \mathrm{L}$, respectively). Urinary triclosan concentrations in our study population were similar to those reported among pregnant women in Spain (43) and New York $(44,45)$, and also among US women from the general population included in the 2011-2012 National Health and Nutrition Examination Survey (NHANES) (46) (medians $=6.1,6.5,11.0$, and $7.6 \mu \mathrm{g} / \mathrm{L}$, respectively).

As shown in Table 1, more women with endometriosis and ovulation disorders were in the group with higher urinary triclosan concentrations than in the group with lower urinary triclosan concentrations. Although this might suggest a possible association between triclosan and infertility diagnosis, any inferences regarding the role of triclosan in the pathogenesis of these disorders should be made cautiously due to the very small sample sizes in these groups. Further research may be warranted to investigate the association between triclosan and the aforementioned reproductive disorders.

Our study has limitations worth noting. Due to its design, it may not be possible to generalize our findings to women who are not seeking fertility evaluation. However, our results may be applicable to other women seeking infertility treatment which is a sizeable population (4747). Also, as is true for all observational studies, misclassification of triclosan exposure based on urinary triclosan concentrations from spot samples is possible because this chemical has a relatively short elimination half-life and exposures to triclosan are likely to be episodic in nature. In addition, we were not able to assess anti-mullerian hormone levels, which is another well-accepted marker of ovarian reserve, in our women. Moreover, this study includes a small sample size. Thus, further research including larger study populations is needed to corroborate the findings. Strengths of our study include its prospective design which minimizes the possibility of reverse causation and our comprehensive adjustment for other reproductive and lifestyle factors that could result in residual confounding.

In conclusion, we found that SG-adjusted urinary triclosan concentrations were inversely associated with total number of antral follicles in women attending a fertility center. This association was stronger among younger women and also among lean women. Since younger women have higher AFC, it is possible that they are more sensitive to the exposure of triclosan. But it is also possible that the effect of triclosan is masked by the effect of age itself among older women. In addition, we speculate that triclosan could be metabolized differently in lean women. Despite the reduction in AFC might not be of clinical significance at the individual patient level, it might be a concern of public health. Our findings could be suggestive of a cumulative effect of chronic triclosan exposure potentially contributing to the reduced fecundability and need to seek treatment for infertility at a younger age. Considering this is the first study investigating the potential effect of triclosan exposure on ovarian reserve among women seeking infertility treatments, further epidemiologic studies assessing longer durations of observation and exposure at different stages of life (i.e., infancy, puberty or adulthood) are warranted to corroborate our results in this and other populations. Also, future research would benefit from including exposure to 
chemical mixtures due to our previous findings of other endocrine disruptors and AFC among women in EARTH Study.

\section{Acknowledgments}

We would like to acknowledge all members of the EARTH study team, specifically the Harvard T. H. Chan School of Public Health research nurse Myra G. Keller, research staff Ramace Dadd and Patricia Morey, physicians and staff at Massachusetts General Hospital fertility center and a special thanks to all the study participants. We thank Xiaoyun Ye, Xiaoliu Zhou, and Tao Jia for technical assistance in the quantification of triclosan.

Study Funding: This work was supported by NIH grants R01ES022955, R01ES009718, and R01ES000002 from the National Institute of Environmental Health Sciences (NIEHS).

\section{References}

1. Fang JL, Stingley RL, Beland FA, Harrouk W, Lumpkins DL, Howard P. Occurrence, efficacy, metabolism, and toxicity of triclosan. Journal of environmental science and health Part C, Environmental carcinogenesis \& ecotoxicology reviews. 2010; 28:147-71.

2. Dann AB, Hontela A. Triclosan: environmental exposure, toxicity and mechanisms of action. Journal of applied toxicology : JAT. 2011; 31:285-311. [PubMed: 21462230]

3. DeSalva SJ, Kong BM, Lin YJ. Triclosan: a safety profile. American journal of dentistry. 1989; 2:185-96. Spec No. [PubMed: 2638179]

4. Calafat AM, Ye X, Wong LY, Reidy JA, Needham LL. Urinary concentrations of triclosan in the U.S. population: 2003-2004. Environmental health perspectives. 2008; 116:303-7. [PubMed: 18335095]

5. Sandborgh-Englund G, Adolfsson-Erici M, Odham G, Ekstrand J. Pharmacokinetics of triclosan following oral ingestion in humans. Journal of toxicology and environmental health Part A. 2006; 69:1861-73. [PubMed: 16952905]

6. Allmyr M, Adolfsson-Erici M, McLachlan MS, Sandborgh-Englund G. Triclosan in plasma and milk from Swedish nursing mothers and their exposure via personal care products. The Science of the total environment. 2006; 372:87-93. [PubMed: 17007908]

7. Hines EP, Mendola P, von Ehrenstein OS, Ye X, Calafat AM, Fenton SE. Concentrations of environmental phenols and parabens in milk, urine and serum of lactating North Carolina women. Reproductive toxicology (Elmsford, NY). 2015; 54:120-8.

8. Calafat AM, Longnecker MP, Koch HM, Swan SH, Hauser R, Goldman LR, et al. Optimal Exposure Biomarkers for Nonpersistent Chemicals in Environmental Epidemiology. Environmental health perspectives. 2015; 123:A166-8. [PubMed: 26132373]

9. United-States. Safety and Effectiveness of Consumer Antiseptics; Topical Antimicrobial Drug Products for Over-the-Counter Human Use. Final rule. 2016; 81:61106-30. [accesed December, 2016] Available at https://www.gpo.gov/fdsys/pkg/FR-2016-09-06/pdf/2016-21337.pdf. Federal register.

10. European-Union. [accesed December, 2016] Comission Regulation (EU) No 358/•2014 - of 9 April 2014 - amending Annexes II and V to Regulation (EC) No 1223/•2009 of the European Parliament and of the Council on cosmetic products. 2014. Available at http://eur-lex.europa.eu/legalcontent/EN/TXT/PDF/?uri=CELEX:32014R0358\&from=RO

11. European-Union. [accesed December, 2016] Comission Implementing Decision (EU) 2016/ 110 of 27 January 2016 -not approving triclosan as an existing active substance for use in biocidal products for product-type 1. 2016. Available at http://eur-lex.europa.eu/legal-content/EN/TXT/ $\mathrm{PDF} /$ ?uri=CELEX:32016D0110\&from $=\mathrm{EN}$

12. Canada-Gazette. [accesed December, 2016] Canada Gazette, Part I: Vol. 150, No. 50 - December 10, 2016. 2016. Available at http://www.gazette.gc.ca/rp-pr/p1/2016/2016-12-10/pdf/ g1-15050.pdf\#page $=88$

13. Zorrilla LM, Gibson EK, Jeffay SC, Crofton KM, Setzer WR, Cooper RL, et al. The effects of triclosan on puberty and thyroid hormones in male Wistar rats. Toxicological sciences : an official journal of the Society of Toxicology. 2009; 107:56-64. [PubMed: 18940961] 
14. Paul KB, Hedge JM, Bansal R, Zoeller RT, Peter R, DeVito MJ, et al. Developmental triclosan exposure decreases maternal, fetal, and early neonatal thyroxine: a dynamic and kinetic evaluation of a putative mode-of-action. Toxicology. 2012; 300:31-45. [PubMed: 22659317]

15. Kim JY, Yi BR, Go RE, Hwang KA, Nam KH, Choi KC. Methoxychlor and triclosan stimulates ovarian cancer growth by regulating cell cycle- and apoptosis-related genes via an estrogen receptor-dependent pathway. Environmental toxicology and pharmacology. 2014; 37:1264-74. [PubMed: 24835555]

16. Lee HR, Hwang KA, Nam KH, Kim HC, Choi KC. Progression of breast cancer cells was enhanced by endocrine-disrupting chemicals, triclosan and octylphenol, via an estrogen receptordependent signaling pathway in cellular and mouse xenograft models. Chemical research in toxicology. 2014; 27:834-42. [PubMed: 24684733]

17. Forte M, Mita L, Cobellis L, Merafina V, Specchio R, Rossi S, et al. Triclosan and bisphenol a affect decidualization of human endometrial stromal cells. Molecular and cellular endocrinology. 2016; 422:74-83. [PubMed: 26604029]

18. Stoker TE, Gibson EK, Zorrilla LM. Triclosan exposure modulates estrogen-dependent responses in the female wistar rat. Toxicological sciences : an official journal of the Society of Toxicology. 2010; 117:45-53. [PubMed: 20562219]

19. Crawford BR, Decatanzaro D. Disruption of blastocyst implantation by triclosan in mice: impacts of repeated and acute doses and combination with bisphenol-A. Reproductive toxicology (Elmsford, NY). 2012; 34:607-13.

20. Den Hond E, Tournaye H, De Sutter P, Ombelet W, Baeyens W, Covaci A, et al. Human exposure to endocrine disrupting chemicals and fertility: A case-control study in male subfertility patients. Environment international. 2015; 84:154-60. [PubMed: 26292060]

21. Velez MP, Arbuckle TE, Fraser WD. Female exposure to phenols and phthalates and time to pregnancy: the Maternal-Infant Research on Environmental Chemicals (MIREC) Study. Fertility and sterility. 2015; 103:1011-20.e2. [PubMed: 25681860]

22. Smarr MM, Sundaram R, Honda M, Kannan K, Buck Louis GM. Urinary Concentrations of Parabens and Other Antimicrobial Chemicals and Their Association with Couples' Fecundity. Environmental health perspectives. 2016

23. Hansen KR, Hodnett GM, Knowlton N, Craig LB. Correlation of ovarian reserve tests with histologically determined primordial follicle number. Fertility and sterility. 2011; 95:170-5. [PubMed: 20522327]

24. Hauser R, Meeker JD, Duty S, Silva MJ, Calafat AM. Altered semen quality in relation to urinary concentrations of phthalate monoester and oxidative metabolites. Epidemiology (Cambridge, Mass). 2006; 17:682-91.

25. Ye X, Kuklenyik Z, Needham LL, Calafat AM. Automated on-line column-switching HPLCMS/MS method with peak focusing for the determination of nine environmental phenols in urine. Analytical chemistry. 2005; 77:5407-13. [PubMed: 16097788]

26. Smith KW, Braun JM, Williams PL, Ehrlich S, Correia KF, Calafat AM, et al. Predictors and Variability of Urinary Paraben Concentrations in Men and Women, Including before and during Pregnancy. Environmental health perspectives. 2012; 120:1538-43. [PubMed: 22721761]

27. Pearson MA, Lu C, Schmotzer BJ, Waller LA, Riederer AM. Evaluation of physiological measures for correcting variation in urinary output: Implications for assessing environmental chemical exposure in children. Journal of exposure science \& environmental epidemiology. 2009; 19:33642. [PubMed: 18841168]

28. Wolf AM, Hunter DJ, Colditz GA, Manson JE, Stampfer MJ, Corsano KA, et al. Reproducibility and validity of a self-administered physical activity questionnaire. International journal of epidemiology. 1994; 23:991-9. [PubMed: 7860180]

29. Mok-Lin E, Ehrlich S, Williams PL, Petrozza J, Wright DL, Calafat AM, et al. Urinary bisphenol A concentrations and ovarian response among women undergoing IVF. International journal of andrology. 2010; 33:385-93. [PubMed: 20002217]

30. Searle SR, Speed FM, Milliken GA. Population marginal means in the linear model: an alternative to least square means. Am Stat. 1980; 34:216-21. 
31. Weng HY, Hsueh YH, Messam LLM, Hertz-Picciotto I. Methods of Covariate Selection: Directed Acyclic Graphs and the Change-in-Estimate Procedure. American journal of epidemiology. 2009; 169:1182-90. [PubMed: 19363102]

32. Rich-Edwards JW, Spiegelman D, Garland M, Hertzmark E, Hunter DJ, Colditz GA, et al. Physical activity, body mass index, and ovulatory disorder infertility. Epidemiology (Cambridge, Mass). 2002; 13:184-90.

33. Baird DT, Collins J, Egozcue J, Evers LH, Gianaroli L, Leridon H, et al. Fertility and ageing. Human reproduction update. 2005; 11:261-76. [PubMed: 15831503]

34. American College of Obstetricians and Gynecologists Committee on Gynecologic Practice and Practice Committee. Female age-related fertility decline. Committee Opinion No. 589. Fertility and sterility. 2014; 101:633-4. [PubMed: 24559617]

35. Luke B, Brown MB, Stern JE, Missmer SA, Fujimoto VY, Leach R. Female obesity adversely affects assisted reproductive technology (ART) pregnancy and live birth rates. Human reproduction (Oxford, England). 2011; 26:245-52.

36. Pollock T, Greville LJ, Tang B, deCatanzaro D. Triclosan elevates estradiol levels in serum and tissues of cycling and peri-implantation female mice. Reproductive toxicology (Elmsford, NY). 2016; 65:394-401.

37. James MO, Li W, Summerlot DP, Rowland-Faux L, Wood CE. Triclosan is a potent inhibitor of estradiol and estrone sulfonation in sheep placenta. Environment international. 2010; 36:942-9. [PubMed: 19299018]

38. Ahn KC, Zhao B, Chen J, Cherednichenko G, Sanmarti E, Denison MS, et al. In vitro biologic activities of the antimicrobials triclocarban, its analogs, and triclosan in bioassay screens: receptorbased bioassay screens. Environmental health perspectives. 2008; 116:1203-10. [PubMed: 18795164]

39. Kolsek K, Gobec M, Mlinaric Rascan I, Sollner Dolenc M. Screening of bisphenol A, triclosan and paraben analogues as modulators of the glucocorticoid and androgen receptor activities.

Toxicology in vitro : an international journal published in association with BIBRA. 2015; 29:8-15. [PubMed: 25192815]

40. Huang H, Du G, Zhang W, Hu J, Wu D, Song L, et al. The in vitro estrogenic activities of triclosan and triclocarban. Journal of applied toxicology : JAT. 2014; 34:1060-7. [PubMed: 24740835]

41. Meeker JD, Cantonwine DE, Rivera-Gonzalez LO, Ferguson KK, Mukherjee B, Calafat AM, et al. Distribution, variability, and predictors of urinary concentrations of phenols and parabens among pregnant women in Puerto Rico. Environmental science \& technology. 2013; 47:3439-47. [PubMed: 23469879]

42. Philippat C, Mortamais M, Chevrier C, Petit C, Calafat AM, Ye X, et al. Exposure to phthalates and phenols during pregnancy and offspring size at birth. Environmental health perspectives. 2012; 120:464-70. [PubMed: 21900077]

43. Casas L, Fernandez MF, Llop S, Guxens M, Ballester F, Olea N, et al. Urinary concentrations of phthalates and phenols in a population of Spanish pregnant women and children. Environment international. 2011; 37:858-66. [PubMed: 21440302]

44. Philippat C, Wolff MS, Calafat AM, Ye X, Bausell R, Meadows M, et al. Prenatal exposure to environmental phenols: concentrations in amniotic fluid and variability in urinary concentrations during pregnancy. Environmental health perspectives. 2013; 121:1225-31. [PubMed: 23942273]

45. Wolff MS, Engel SM, Berkowitz GS, Ye X, Silva MJ, Zhu C, et al. Prenatal phenol and phthalate exposures and birth outcomes. Environmental health perspectives. 2008; 116:1092-7. [PubMed: 18709157]

46. CDC. Centers for Disease Control and Prevention. Fourth Report on Human Exposure to Environmental Chemicals, Updated Tables. Atlanta, GA, USA: Department of Health and Human Services, Centers for Disease Control and Prevention; Feb. 2015 http://www.cdc.gov/ biomonitoring/pdf/FourthReport_UpdatedTables_Feb2015.pdf2015 [accesed December, 2016]

47. Thoma ME, McLain AC, Louis JF, King RB, Trumble AC, Sundaram R, et al. Prevalence of infertility in the United States as estimated by the current duration approach and a traditional constructed approach. Fertility and sterility. 2013; 99:1324-31.e1. [PubMed: 23290741] 

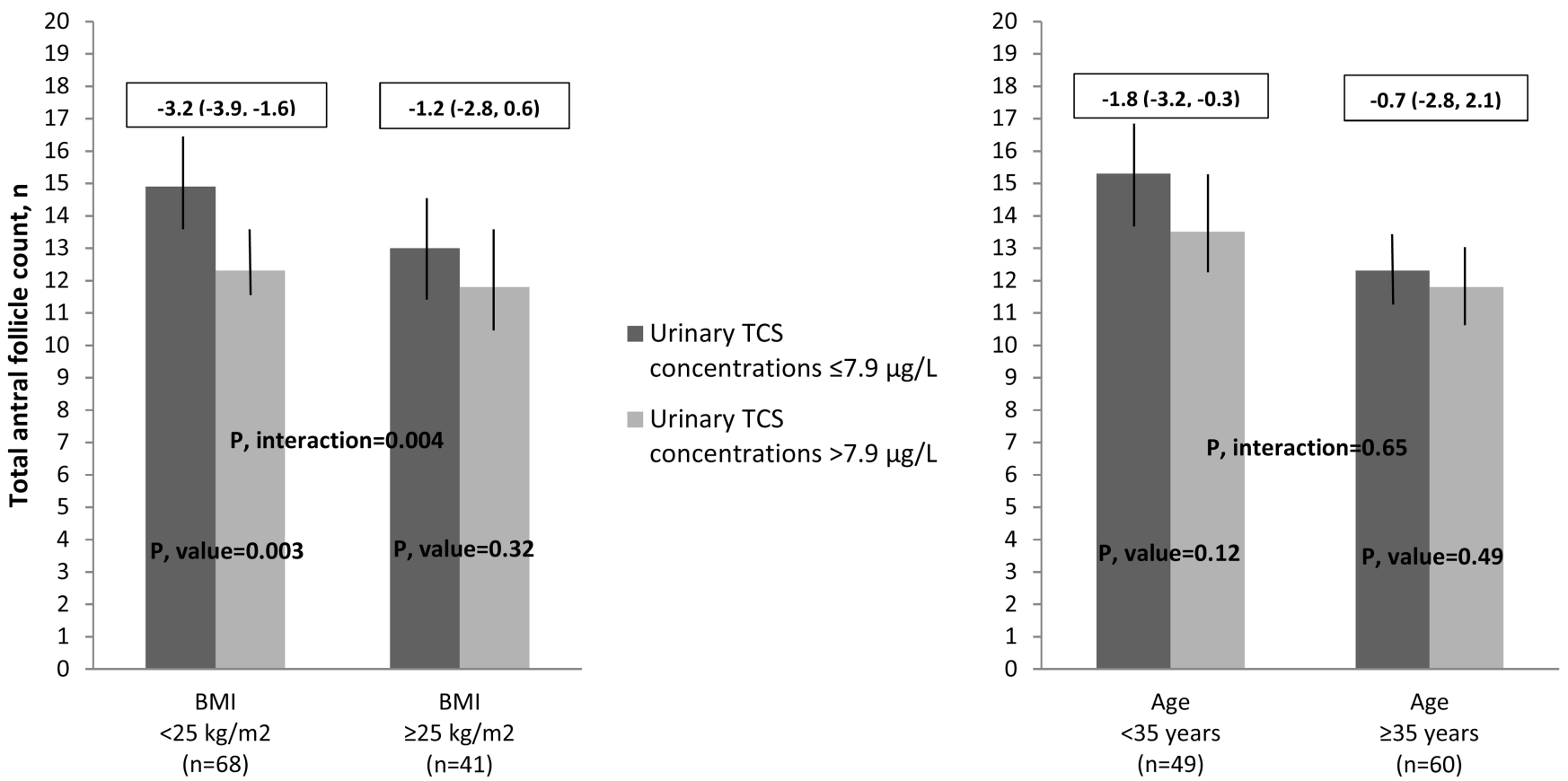

Figure 1. Effect modification by age and BMI on the association between $\mathrm{AFC}^{\mathrm{a}}$ and $\mathrm{SG}$-adjusted urinary triclosan concentrations among 109 women in the EARTH Study

Abbreviations: BMI, body mass index; TCS, triclosan; AFC, Total antral follicle count;

EARTH, Environmental and Reproductive Health. aData are presented as predicted marginal means (95\% CI) adjusted for year of sample collection ( $ک 2012$ and >2012), physical activity (hr/week), and infertility diagnosis (male, female and unexplained). Models exploring the effect of modification by age were further adjusted for BMI $(\mathrm{kg} / \mathrm{m} 2)$, and models exploring the effect of modification by BMI were further adjusted for age (years). Note: the boxes above the graphics represent the AFC differences (mean and 95\% CI) for women below and above median SG-adjusted urinary TCS concentrations. 


\section{Table 1}

Baseline demographic and reproductive characteristics ${ }^{a}$ by specific gravity (SG)-adjusted urinary triclosan concentrations $(\mu \mathrm{g} / \mathrm{L})$ of 109 women in the EARTH Study.

\begin{tabular}{|c|c|c|c|c|}
\hline & \multirow[b]{2}{*}{ Total Cohort (n=109) } & \multicolumn{3}{|c|}{ SG-adjusted urinary triclosan concentrations } \\
\hline & & $<7.9 \mu \mathrm{g} / \mathrm{L}(\mathrm{n}=54)$ & $>7.9 \mu \mathrm{g} / \mathrm{L}(\mathrm{n}=55)$ & P-value ${ }^{b}$ \\
\hline \multicolumn{5}{|l|}{ Demographic characteristics } \\
\hline Age, years & $36.0(32.0,38.0)$ & $36.0(32.0,39.0)$ & $35.0(32.0,37.0)$ & 0.27 \\
\hline Race/Ethnic group, n (\%) & & & & 0.31 \\
\hline White/Caucasian & $85(78.0)$ & $44(81.5)$ & $41(74.6)$ & \\
\hline Black & $2(1.8)$ & $2(3.7)$ & $0(0)$ & \\
\hline Asian & $11(10.1)$ & $4(7.4)$ & $7(12.7)$ & \\
\hline Other & $11(10.1)$ & $4(7.4)$ & $7(12.7)$ & \\
\hline Body Mass Index, $\mathrm{kg} / \mathrm{m}^{2}$ & $23.0(20.9,26.5)$ & $23.8(21.0,27.0)$ & $22.7(20.6,26.5)$ & 0.47 \\
\hline Smoking status, n (\%) & & & & 0.28 \\
\hline Never smoked & $79(72.5)$ & $42(77.8)$ & $37(67.3)$ & \\
\hline Ever smoked & $30(27.5)$ & $12(22.2)$ & $18(32.7)$ & \\
\hline Education $^{c}, \mathrm{n}(\%)$ & & & & 0.25 \\
\hline$<$ College graduate & $8(7.3)$ & $3(5.5)$ & $5(9.0)$ & \\
\hline College graduate & $33(30.3)$ & $21(38.9)$ & $12(21.8)$ & \\
\hline Graduate degree & $54(49.5)$ & $24(44.4)$ & $30(54.5)$ & \\
\hline Total physical activity (hr/week) & $5.0(2.0,10.0)$ & $4.0(1.4,8.6)$ & $6.5(2.0,11.5)$ & 0.19 \\
\hline \multicolumn{5}{|l|}{ Reproductive characteristics } \\
\hline History of ever been pregnant, $\mathrm{n}(\%)$ & $41(37.6)$ & $23(42.6)$ & $18(32.7)$ & 0.33 \\
\hline History of been treated for infertility ${ }^{c}, \mathrm{n}(\%)$ & $40(36.7)$ & $21(38.9)$ & $19(34.5)$ & 0.83 \\
\hline Previous infertility exam ${ }^{c}, \mathrm{n}(\%)$ & $85(78.0)$ & $40(74.0)$ & $45(81.8)$ & 0.63 \\
\hline Day 3 FSH Levels, IU/L & $6.6(5.6,8.1)$ & $6.9(6.0,8.8)$ & $6.4(5.4,7.6)$ & 0.08 \\
\hline Initial infertility diagnosis, $\mathrm{n}(\%)$ & & & & 0.05 \\
\hline Male factor & $19(17.4)$ & $7(13.0)$ & $12(21.8)$ & \\
\hline Female factor & $36(33.0)$ & $14(25.9)$ & $22(40.0)$ & \\
\hline Diminished Ovarian Reserve & $6(5.5)$ & $5(9.3)$ & $1(1.8)$ & \\
\hline Endometriosis & $7(6.4)$ & $2(3.7)$ & $5(9.1)$ & \\
\hline Ovulation Disorders & $14(12.8)$ & $4(7.4)$ & $10(18.2)$ & \\
\hline Tubal & $4(3.7)$ & $2(3.7)$ & $2(3.6)$ & \\
\hline Uterine & $5(4.6)$ & $1(1.9)$ & $4(7.3)$ & \\
\hline Unexplained & $54(49.6)$ & $33(61.1)$ & $21(38.2)$ & \\
\hline
\end{tabular}

Abbreviations: IQR, interquartile range; N, number, EARTH, Environmental and Reproductive Health; SG, specific gravity.

${ }^{a}$ Values are presented as median (IQR) unless otherwise noted.

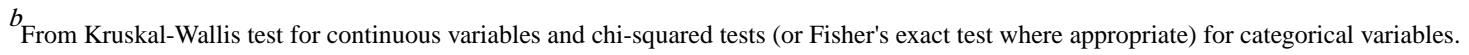

$c_{\text {These variables have missing data. }}$

Fertil Steril. Author manuscript; available in PMC 2018 August 01. 


\section{Table 2}

Distribution of woman-specific urinary triclosan concentrations $(\mu \mathrm{g} / \mathrm{L})$ among 109 women $(\mathrm{n}=225 \mathrm{urines})$ in the EARTH Study.

\begin{tabular}{lcccc} 
& Detection Frequency $(\%)$ & GM (95\% CI) & $\mathbf{5 0}^{\text {th }}$ Percentile & $\mathbf{7 5}^{\text {th }} \mathbf{M a x}^{\text {Percentile }}$ \\
\hline $\begin{array}{l}\text { Urinary triclosan concentrations SG-adjusted } \\
\text { urinary triclosan concentrations }\end{array}$ & 75 & $10.7(7.1,16.0)$ & 6.04 & 32.93930 \\
& - & $13.0(8.9,19.1)$ & 7.88 & 33.62456 \\
\hline
\end{tabular}

Abbreviations: AFC, total antral follicle count; <LOD, limit of detection for TCS (2.3 $\mu \mathrm{g} / \mathrm{L})$; Max, maximum; SG-adjusted, specific-gravity adjusted; EARTH, Environmental and Reproductive Health. 


\section{Table 3}

$\mathrm{AFC}^{a}$ by SG-adjusted urinary triclosan concentrations among 109 women in the EARTH Study.

\begin{tabular}{lcc}
\hline SG-adjusted urinary triclosan concentrations $(\boldsymbol{\mu g} / \mathbf{L})$ & \multicolumn{2}{c}{ AFC, $\mathbf{n}$} \\
& Unadjusted & Adjusted $^{b}$ \\
\hline Continuous $\log _{\mathrm{e}}$-scale $($ P-estimate and $95 \% \mathrm{CI})$ & $-0.03(-0.05,-0.02)$ & $-0.04(-0.07,-0.01)$ \\
$\quad p$-value & 0.04 & 0.009 \\
\hline Lower group $(57.9 \mu \mathrm{g} / \mathrm{L})$ & $13.7(12.8,14.8)$ & $13.9(12.9,14.9)$ \\
Higher group $(>7.9 \mu \mathrm{g} / \mathrm{L})$ & $13.1(12.2,14.1)$ & $12.9(11.9,14.2)$ \\
$\quad$ Difference & $-0.6(-1.5,0.4)$ & $-1.0(-2.0,0.3)$ \\
$p$-value & 0.37 & 0.18 \\
\hline
\end{tabular}

Abbreviations: AFC, Total antral follicle count; EARTH, Environmental and Reproductive Health; n, number; SG, specific gravity.

${ }^{a}$ Data are presented as predicted marginal means $(95 \% \mathrm{CI})$ unless otherwise noted.

${ }^{b}$ Models are adjusted for age (years), BMI ( $\mathrm{kg} / \mathrm{m}^{2}$ ), year of sample collection ( 2012 and $>2012$ ), physical activity (hr/week), and infertility diagnosis (male, female and unexplained). 